\title{
Clinico-Epidemiological Pattern and Treatment of Epistaxis in a Tertiary Hospital in South Western Nigeria
}

\author{
Waheed Atilade Adegbiji ${ }^{1}$, Gabriel Toye Olajide ${ }^{2 *}$, \\ Fatai Olatoke ${ }^{3}$, Clement Chukwuemeka Nwawolo ${ }^{4}$ \\ ${ }^{1}$ ENT Department, Ekiti State University Teaching Hospital, Ado Ekiti, Nigeria \\ ${ }^{2}$ ENT Department, Federal Teaching Hospital, Ido Ekiti, Nigeria \\ ${ }^{3}$ ENT Unit, Department of Surgery, Federal Medical Centre, Lokoja, Nigeria \\ ${ }^{4}$ ENT Department, Lagos University Teaching Hospital, Lagos, Nigeria \\ Email: awagbiji@yahoo.com, *toyeolajide@yahoo.co.uk, olatokef@yahoo.com,clementnwawolo@yahoo.com
}

How to cite this paper: Adegbiji, W.A., Olajide, G.T., Olatoke, F. and Nwawolo, C.C. (2018) Clinico-Epidemiological Pattern and Treatment of Epistaxis in a Tertiary Hospital in South Western Nigeria. International Journal of Otolaryngology and Head \& Neck Surgery, 7, 88-97.

https://doi.org/10.4236/ijohns.2018.73012

Received: April 2, 2018

Accepted: May 14, 2018

Published: May 17, 2018

Copyright $\odot 2018$ by authors and Scientific Research Publishing Inc. This work is licensed under the Creative Commons Attribution International License (CC BY 4.0).

http://creativecommons.org/licenses/by/4.0/

\begin{abstract}
Background/Objectives: Epistaxis is a common presentation and may constitute a major challenge to the parents and the health care givers. This study aimed at determining the clinico-epidemiological pattern, presentation and etiology of epistaxis. Materials and Methods: This prospective study of all patients that presented with epistaxis via the Ear, Nose and Throat department of a tertiary institution in Nigeria. The study was carried out between June 2012 and July 2017. Data were obtained from patients who gave consent by using pre-tested interviewer assisted questionnaire. All the data obtained were analyzed using SPSS version 16.0. Results: The prevalence of epistaxis in this study was $12.2 \%$. The peak age group was $1-10$ years with epistaxis prevalence of $36.4 \%$. The male to female ratio was $1.5: 1$. Anterior epistaxis was more common than posterior epistaxis accounted for $80.1 \%$ and $7.4 \%$ respectively. Single episode of epistaxis was seen in $78.4 \%$ of the patients while recurrent epistaxis occurred in $21.6 \%$. Unilateral epistaxis was $62.5 \%$, bilateral epistaxis was $37.5 \%$ while right nasal bleeding accounted for $35.8 \%$. The main local causes of epistaxis were trauma $29.5 \%$, infective rhinosinusitis $18.8 \%$ and sinonasal tumours $12.5 \%$. Severe epistaxis requiring blood transfusion was seen in $2.8 \%$ of the patients and death was recorded in $2.3 \%$. Majority 110 (62.5\%) were managed by observation alone, 20 (11.4\%) by conservative therapy and $22(12.5 \%)$ had surgical excision. Blood transfusion was given in 5. The outcome of treatment was good recovery in $79.0 \%$ while patients' satisfaction with treatment was noted in $84.1 \%$. Conclusion: Epistaxis is a common sinonasal presentation with effect on quality of life. In our center commonest site of nose bleeds was local mainly from traumatic, inflammatory and
\end{abstract}


neoplastic aetiology.

\section{Keywords}

Epistaxis, Aetiology, Nose, South Western Nigeria

\section{Introduction}

Epistaxis which is bleeding from the nose is a common presentation in otorhinolaryngological, head and neck practice worldwide [1]. It may present as an emergency in the casualty or in the ear, nose and throat out-patient clinic [2]. Nose bleeding may be sudden or insidious in onset. It could be induced or spontaneous. Epistaxis may present as anterior, posterior or both anterior and posterior nose bleeding. The sight of blood in the nose leads most patients to seek early medical intervention. Finally, nose bleeding may be unilateral or bilateral. Epistaxis occurs in about $60 \%$ of children worldwide during their lifetime [3] [4] [5] [6]. In the prevalence of epistaxis males are slightly more affected than females until the age of 50 years [7].

The nose is the most prominent mid facial organ occupying the middle third of the face. The nasal cavity is highly vascularized with blood supply from branches of the internal and external carotid arteries. One of the two important and commonest areas in the nose bleeding is Kiesselbach's plexus (anterior bleeds), also known as Little's area, located on the anterior inferior part nasal septum [8]. The second area is Woodruff's plexus (posterior bleeds), located over the posterior middle turbinate [9].

The causes of epistaxis have been broadly classified into local causes (relating to problems in the nose, paranasal sinuses and the nasopharynx) and systemic causes (haematological, hepatic, cardiovascular, renal and drugs) [10] [11] [12].

Severe epistaxis or chronic epistaxis may be life threatening in patients or leads to shock and eventually deaths if not properly managed. Other complication of nose bleeding includes anaemia, hypovolaemia and shock.

Patients with ongoing nose bleeding often require an immediate arrest of the bleeding and need for immediate intervention to be stabilized before detail assessment. Management of stable patients requires detailed history and examination. Management of the patients could be local or general and may also be surgical or medical depending on the aetiology and associated complications [12] [13] [14] [15]. There is paucity of literature on epistaxis in developing countries.

This study aimed at determining the clinico-epidemiological pattern of presentation of epistaxis, the etiology, management options and outcomes of management, in Ado Ekiti, Nigeria.

\section{Materials and Methods}

This a prospective hospital based study of all consecutive patients that presented 
with epistaxis via the ENT clinics, the hospital wards and the accident and emergency units of a state university teaching hospital in Ado Ekiti Nigeria. The study was carried out between June 2012 and July 2017 (over 5 years). Data were obtained from the patients by using pre tested interviewer assisted questionnaire. Informed consent was obtained from patients. Firstly patients with ongoing nose bleeding were given first aid to stabilize them. Evaluation of all stable patients included detailed history taking on sociodemographic features, aetiological factors, past medical and surgical history of epistaxis. Thorough clinical examination, anterior rhinoscopy and rigid nasoendoscopy were performed where indicated. Other head and neck with general examination were performed on each patient. Further information on mode of treatment, complication, blood transfusion, duration of hospitalization and outcome of management of epistaxis were documented.

All the data obtained were collated and analyzed using SPSS version 16.0. The data were expressed by using tables, percentages, bar charts and pie charts.

Ethical approval to conduct the study was sought from the institution ethic review committee and obtained.

\section{Results}

During the study period, 1439 patients were seen out of which 176 patients had epistaxis. The prevalence of epistaxis was $12.2 \%$. Figure 1 illustrated the age group distribution of the patients with epistaxis. There were 106 (60.2\%) males and $70(39.8 \%)$ females with a male to female ratio of 1.5:1. Majority 97 (55.1\%) of the epistaxis patients were urban dwellers. The commonest level of education were primary in 59 (33.5\%) followed by preschool in 48 (27.3\%). The main patients' occupations were 64 (36.4\%) student/apprentice and 29 (16.5\%) farming. Others were $2(1.1 \%)$ health workers and industrial workers $17(9.7 \%)$. This is illustrated in Table 1.

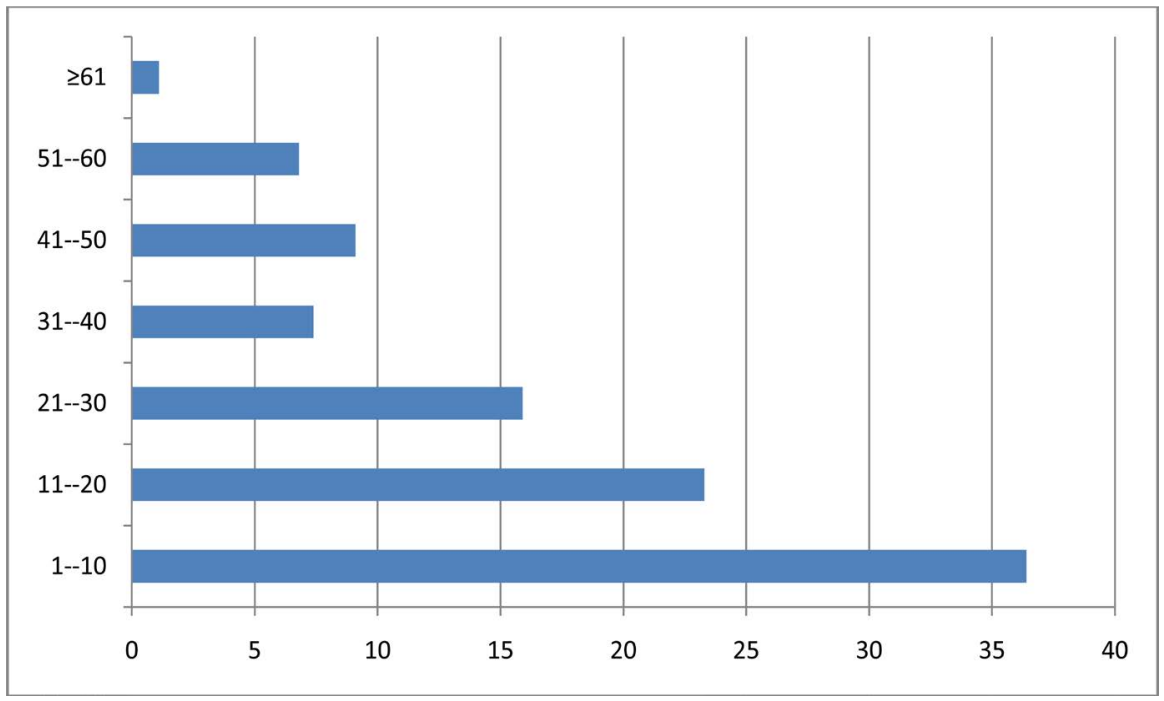

Figure 1. Age group (years) distribution of the patients with epistaxis. 
Table 1. Sociodemographic features of patients with epistaxis $(\mathrm{N}=176)$.

\begin{tabular}{|c|c|c|}
\hline Sociodemographic features (variable) & Number (n) & Percentage (\%) \\
\hline \multicolumn{3}{|l|}{ Sex } \\
\hline Male & 106 & 60.2 \\
\hline Female & 70 & 39.8 \\
\hline \multicolumn{3}{|l|}{ Residential } \\
\hline Urban & 97 & 55.1 \\
\hline Rural & 79 & 44.9 \\
\hline \multicolumn{3}{|l|}{ Education level } \\
\hline Preschool & 48 & 27.3 \\
\hline Primary & 59 & 33.5 \\
\hline Secondary & 42 & 23.9 \\
\hline Post secondary & 27 & 15.3 \\
\hline \multicolumn{3}{|l|}{ Patients occupation } \\
\hline Student/Apprentice & 64 & 36.4 \\
\hline Applicant & 24 & 13.6 \\
\hline Business & 26 & 14.8 \\
\hline Teaching & 18 & 10.2 \\
\hline Industrial worker & 17 & 9.7 \\
\hline Farming & 29 & 16.5 \\
\hline Health worker & 2 & 1.1 \\
\hline
\end{tabular}

In this study anterior epistaxis was seen in $141(80.1 \%)$, posterior epistaxis in $13(7.4 \%)$ and both (anterior and posterior) were found in $22(12.5 \%)$. There were single episode of epistaxis in 138 (78.4\%) over recurrent epistaxis in 38 (21.6\%). Unilateral epistaxis was seen in $110(62.5 \%)$ and bilateral epistaxis in 66 (37.5\%) while right nasal bleeding accounted for 63 (35.8\%). It was noted that $114(64.8 \%)$ patients lost less than $200 \mathrm{ml}$ of blood compared to $62(35.2 \%)$ patients who lost over $200 \mathrm{ml}$ of blood. Characteristics of epistaxis among the patients were illustrated in Table 2.

Local causes of epistaxis accounted for 150 (85.2\%) while general causes accounted for $26(14.8 \%)$. Main causes of epistaxis was trauma in $52(29.5 \%)$ followed by infective rhinosinusitis in $33(18.8 \%)$ and sinonasal tumour in 22 (12.5\%). Less common causes were septiceamia, chronic renal failure and nasopharyngeal carcinoma in $2(1.1 \%), 3(1.7 \%)$ and $3(1.7 \%)$ respectively. This is illustrated in Table 3.

Major sources of referral were emergency department of the hospital and general practitioners which were $63(35.8 \%)$ and $41(23.3 \%)$ respectively. Minor referral were from paediatricians in 28 (15.9\%) and self reporting 27 (15.3\%). Figure 2 demonstrated sources of referral of the patients with epistaxis. Epistaxis leads to absenteeism in $86(48.9 \%)$ and irritable in 79 (44.9\%). Others were 59 (33.5\%) depression and 67 (38.1\%) social dysfunction. Quality of life among patients with epistaxis is demonstrated in Figure 3. In this study, 98 (55.7\%) patients presented through the accident and emergency department and 63 
(35.8\%) presented in the ear nose and throat clinic. There were associated recurrent epistaxis in $37(21.0 \%)$ and vomiting in 34 (19.3\%). Death was recorded in $4(2.3 \%)$. Majority $110(62.5 \%)$ were managed by observation alone, 20 (11.4\%) by conservative therapy, while $22(12.5 \%)$ had surgical excision. Minority had blood transfusion in $5(2.8 \%)$ and posterior nasal packing in $3(1.7 \%)$. The outcome of treatment was good recovery in 139 (79.0\%) while patients' satisfaction with treatment was noted in 148 (84.1\%). This is fully illustrated in Table 4.

Table 2. Characteristics of epistaxis among the patients $(\mathrm{N}=176)$.

\begin{tabular}{ccc}
\hline Characteristics & Number (n) & Percentage (\%) \\
\hline Area of bleeding & 141 & 80.1 \\
Anterior & 13 & 7.4 \\
Posterior & 22 & 12.5 \\
Both & & \\
Recurrence & 138 & 78.4 \\
Single episode & 38 & 21.6 \\
Recurrent & & \\
Duration & 149 & 84.7 \\
Acute $(<3 / 12)$ & 27 & 15.3 \\
Chronic $(>3 / 12)$ & & 35.8 \\
Laterality & 63 & 26.8 \\
Right & 47 & 37.5 \\
Left & 66 & 64.8 \\
Bilateral & & 35.2 \\
Estimated blood loss & 114 & \\
$<200 \mathrm{ml}$ & 62 & \\
$>200 \mathrm{ml}$ & &
\end{tabular}

Table 3. Aetiology of epistaxis among the patients $(\mathrm{N}=176)$.

\begin{tabular}{ccc}
\hline Aetiology & Number & Percentage (\%) \\
\hline Trauma & 52 & 29.5 \\
Foreign body & 14 & 8.0 \\
Allergic rhinitis & 7 & 4.0 \\
Infective rhinitis & 33 & 18.8 \\
Sinonasal tumour & 22 & 12.5 \\
Nasopharyngeal carcinoma & 3 & 1.7 \\
Hypertension & 11 & 6.3 \\
Septiceamia & 2 & 1.1 \\
Chronic renal failure & 3 & 1.7 \\
Sickle cell diseases & 4 & 2.3 \\
Idiopathic & 19 & 10.8 \\
Others & 6 & 3.4 \\
\hline
\end{tabular}




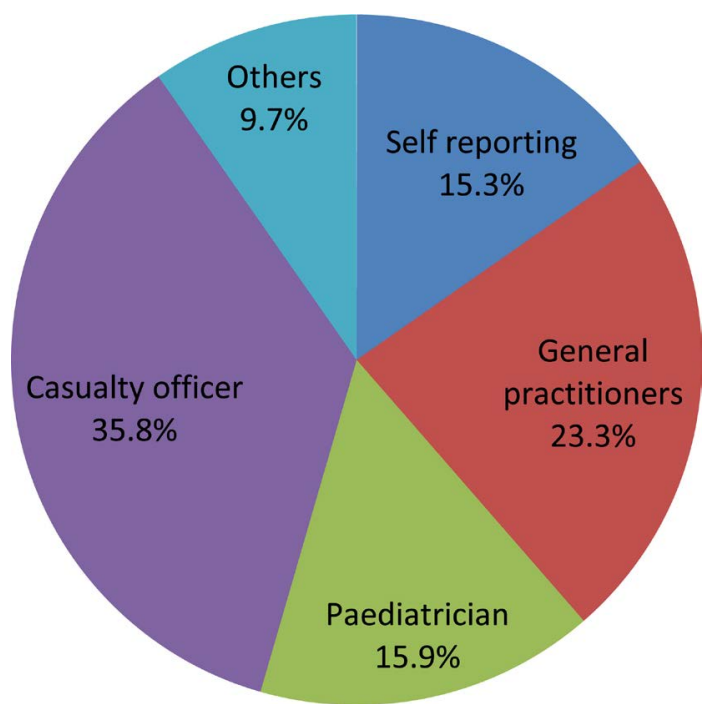

Figure 2. Sources of referral of the patients with epistaxis.

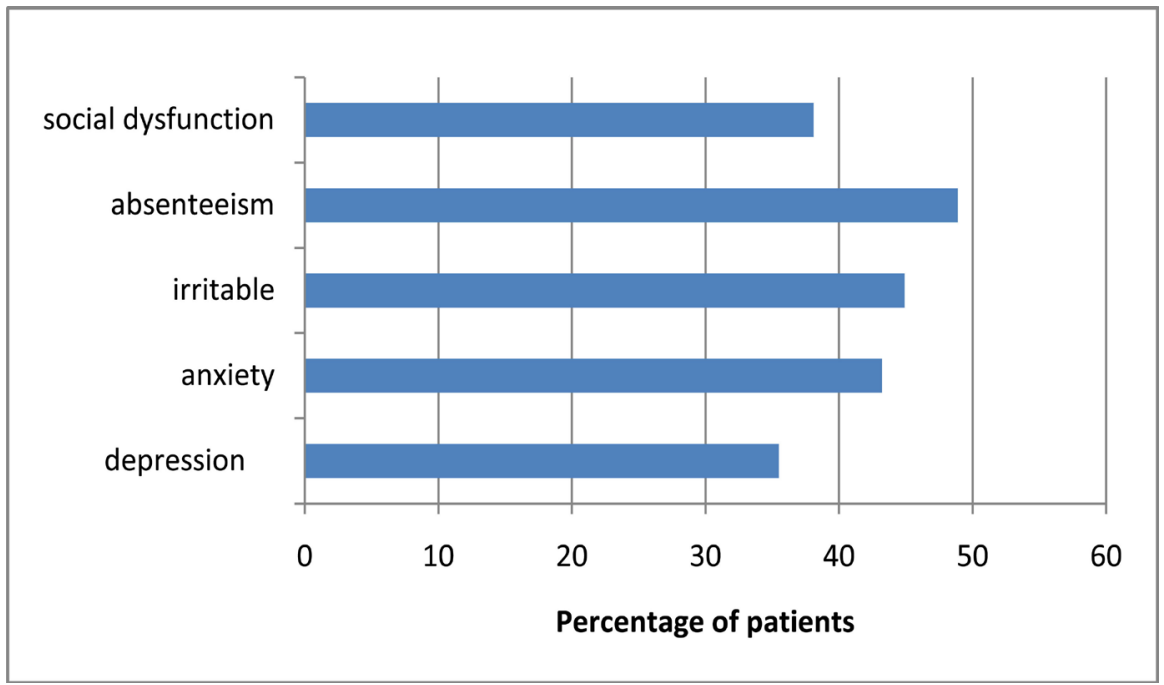

Figure 3. Quality of life among patients with epistaxis.

\section{Discussion}

Epistaxis is one of the common nasal symptoms encountered in most otorhinolaryngological, head and neck practice. In this study, epistaxis accounted for $12.2 \%$ of all patients seen in ear, nose and throat department. Previous record from other studies revealed higher prevalence in their findings [3] [16] [17]. The lower prevalence in this study is due to larger number of patients seen while other study reviewed only emergency patients.

In this study of nose bleeding, young age group (preschool age group) are more commonly affected than the adults. Preschool ages are prone to different nasal injuries, higher incidence of poorly treated rhinitis and nasal foreign body impaction. The foreign body impaction may either be improperly removed or unnoticed with secondary infected. This finding is contrary to record from other study with adult or elderly with higher prevalence [18] [19] [20]. The findings in 
Table 4. Treatment pattern among the patients with epistaxis $(\mathrm{N}=176)$

\begin{tabular}{|c|c|c|}
\hline Treatment patterns & Number (n) & Percentage (\%) \\
\hline \multicolumn{3}{|l|}{ Location of treatment } \\
\hline Ear Nose and Throat clinic & 98 & 55.7 \\
\hline Hospital ward & 15 & 8.5 \\
\hline Accident and emergency department & 63 & 35.8 \\
\hline \multicolumn{3}{|l|}{ Associated complications } \\
\hline Anaemia & 32 & 18.2 \\
\hline Recurrent epistaxis & 37 & 21.0 \\
\hline Vomiting & 34 & 19.3 \\
\hline Death & 4 & 2.3 \\
\hline \multicolumn{3}{|l|}{ Management } \\
\hline Observation alone & 110 & 62.5 \\
\hline Anterior nasal packing & 16 & 9.1 \\
\hline Posterior nasal packing & 3 & 1.7 \\
\hline Other Conservative therapy & 20 & 11.4 \\
\hline Surgical Excision & 22 & 12.5 \\
\hline Blood transfusion & 5 & 2.8 \\
\hline \multicolumn{3}{|l|}{ Outcome of treatment } \\
\hline Good recovery & 139 & 79.0 \\
\hline Hospital stay (days) & 37 & 21.0 \\
\hline \multicolumn{3}{|l|}{ Patients satisfaction } \\
\hline Satisfactory & 148 & 84.1 \\
\hline Unsatisfactory & 28 & 15.9 \\
\hline
\end{tabular}

this study is in agreement with reports of other workers who found epistaxis more in younger age patents [21] [22].

There was male preponderance among patients seen in this study compares well with other reports on nose bleeding from other studies [21] [22]. Men are highly adventurous group, more prone to injuries and exposed to road traffic accidents as drivers (of vehicles and motorcycles) and as frequent travelers in motor vehicles for work and leisure activities [3].

Present study shows the most common cause of epistaxis was local to nose and secondary to trauma first followed by various form of rhinosinusitis and sinonasal tumour. The other causes were idiopathic and hypertension. This findings is consistent with other studies [3] [19]. Most of the patients with nose bleeding arise from traumas that were from road traffic injury, digital, iatrogenic and foreign body impaction. Findings in other studies cite idiopathic causes as the commonest [22] [23].

About three quarter of the patients in our study presented with anterior nasal bleeding. The bleeding is mostly from little's area. This corresponds with findings from other study which demonstrated that almost all of the epistaxis in patients originates from Little's area [24]. Patients with short history of epistaxis were commoner in this study than long standing nose bleeding. This may be be- 
cause of frightened effect of sight of blood from the nose. Furthermore, most of the studied patients present with single episode of epistaxis rather than recurrent epistaxis. This may be a resultant effect of treatable causes of epistaxis such as trauma and infection in this study. Unilateral epistaxis accounted for more than half nose bleeds in this study. The findings may be due to unilateral sinonasal tumour in the studied patients.

On the sources of referral of epistaxis patients for otorhinolaryngological expert review and management in this study were mainly from casualty officer and paediatrician followed by general practitioners. This may be because these are first contact of the patients. This is contrary to record of bleeding diathesis in most attending emergency department in previous study [25] [26].

Nose bleeding was recorded in literature as a source of concerned to the patients, relations and managing physician [27]. In this study there are many effects on quality of life the studied patients. These are noted in anxiety, absenteeism, irritable and depression. The causes may be site of blood and discomfort from the cause of nose bleeding. Majority of the patients were either reviewed or managed in the accident and emergency department or ear, nose and throat clinic. The associated complications during first review were mild anaemia, vomiting which contained altered blood and recurrent epistaxis.

In previous studies, treatment of epistaxis requires a systematic and methodical approach. This treatment options vary according to the cause, location, and severity of the hemorrhage [5] [8]. Like in other study observational, conservative and surgical treatment modalities have been used in the management of epistaxis in the patients [9]. Observation treatment when bleeding has stopped with further treatment like nasal decongestants were instituted. The conservative treatment for anterior or posterior epistaxis includes firm pressure over bleeding area (little's area) with thumb and index finger. If failed anterior with or without posterior nasal packing is performed with much success in our practices. Most of our patients in this study have their epistaxis controlled by conservative measures which include mere observation, use of decongestant and Etamsylate. Some however had anterior and posterior nasal packing done with glove finger and Foley's catheter respectively. Those that had Sino nasal tumour had surgical excision. It is important to note that sophisticated equipment for arterial embolisation, cryosurgery and endoscopic cautery are not available in our center. Surgical control of epistaxis is performed such as nasal tumour excision. Only $2.8 \%$ patient had blood transfusion and we recorded death in $2.3 \%$ patients. Almost all the patients had good outcome and majority were satisfy with the treatment given.

\section{Limitation}

Limitations in this study are lack of sophisticated methods of managing nose bleeding in developing countries. These include use of cryotherapy, posterior endoscopic cautery and arterial embolization that are used in the developed 
countries.

\section{Conclusion}

In this study traumatic and inflammatory causes remain the most common etiological factor for epistaxis. Of all the multiple methods of treatment, our experience shows that safe and cost-effective conservative approach is sufficient in the management of most of our patients and surgical intervention should be the last resort. Effective and safe practices against trauma and infection will reduce the incidence of epistaxis.

\section{Competing Interests}

All the authors declare that there was no competing interest.

\section{References}

[1] Abdel Wahab, M.S., Fathy, H., Ismail, R. and Mahmoud, N. (2014) Recurrent Epistaxis in Children: When Should We Suspect Coagulopathy? The Egyptian Journal of Otolaryngology, 30, 106-111. https://doi.org/10.4103/1012-5574.133207

[2] Hussain, G., Iqbal, M., Shah, S.A., Said, M., Sanaullah, Khan, S.A., et al. (2006) Evaluation of Aetiology and Efficacy of Management Protocol of Epistaxis. Journal of Ayub Medical College, Abbottabad, 18, 63-66.

[3] Akinpelu, O.V., Amusa, Y.B., Eziyi, J.A. and Nwawolo, C.C. (2009) A Retrospective Analysis of Aetiology and Management of Epistaxis in a South-Western Nigerian Teaching Hospital. West African Journal of Medicine, 28, 165-168. https://doi.org/10.4314/wajm.v28i3.48443

[4] Chu, Y.-H. and Lee, J.-C. (2009) Unilateral Epistaxis. The New England Journal of Medicine, 361, 14. https://doi.org/10.1056/NEJMicm0807268

[5] Ciaran, S.H. and Owain, H. (2009) Update on Management of Epistaxis. West London Medical Journal, 1, 33-41.

[6] Walker, T.W.M., Macfarlane, T.V. and McGarry, G.W. (2007) The Epidemiology and Chronobiology of Epistaxis: An Investigation of Scottish Hospital Admissions 1995-2004. Clinical Otolaryngology, 32, 361-365. https://doi.org/10.1111/j.1749-4486.2007.01530.x

[7] Pond, F. and Sizeland, A. (2000) Epistaxis. Strategies for Management. Australian Family Physician, 29, 933-938.

[8] Nash, C.M. and Field, S.M.B. (2008) Epidemiology of Epistaxis in a Canadian Emergency Department. Israeli Journal of Emergency Medicine, 8, 24-28.

[9] Pope, L.E.R. and Hobbs, C.G.L. (2005) Epistaxis: An Update on Current Management. Postgraduate Medical Journal, 81, 309-314.

https://doi.org/10.1136/pgmj.2004.025007

[10] Chauhan, J.P.S., Singh, A.B. and Kumar, A. (2016) A Prospective Analysis of Etiology and Efficacy of Various Treatment Modalities Used in Epistaxis at a Tertiary Care Teaching Hospital. Indian Journal of Basic and Applied Medical Research, 5, 750-755.

[11] Pallin, D.J., Chng, Y., McKay, M.P., Emond, J.A., Pelletier, A.J. and Camargo, C.A. (2005) Epidemiology of Epistaxis in US Emergency Departments 1992 to 2001. Annals of Emergency Medicine, 46, 77-81.

https://doi.org/10.1016/j.annemergmed.2004.12.014 
[12] Bernius, M. and Perlin, D. (2006) Pediatric Ear, Nose, and Throat Emergencies. Pediatric Clinics of North America, 53, 195-210. https://doi.org/10.1016/j.pcl.2005.10.002

[13] Middleton, M.P. (2004) Epistaxis. Emergency Medicine Australasia, 16, 428-440. https://doi.org/10.1111/j.1742-6723.2004.00646.x

[14] Daudia, A., Jaiswal, V. and Jones, N.S. (2008) Guidelines for the Management of Idiopathic Epistaxis in Adults: How We Do It. Clinical Otolaryngology, 33, 607-628. https://doi.org/10.1111/j.1749-4486.2008.01795.x

[15] Gilyoma, J.M. and Chalya, P.L. (2011) Etiological Profile and Treatment Outcome of Epistaxis at a Tertiary Care Hospital in Tanzania: A Prospective Review of 104 Cases. BMC Ear, Nose and Throat Disorders, 11, 8. https://doi.org/10.1186/1472-6815-11-8

[16] Vaamonde Lago, P., Martin, C., Lechuga Garcia, M.R., Minguez Beltran, I. and Labella Caballero, T. (2004) Epidemiological Notes on Nasal Bleeding. Anales Otorrinolaringologicos Ibero-Americanos, 31, 123-132.

[17] Huang, C.L. and Shu, C.H. (2002) Epistaxis: A Review of Hospitalized Patients. Chinese Medical Journal, 65, 74-78.

[18] Ekere, A.U., Yellowe, B.F. and Umune, S. (2005) Mortality Patterns in the Accident and Emergency Department of an Urban Hospital in Nigeria. Nigerian Journal of Clinical Practice, 8, 14-18.

[19] Eziyi, J.A.E., Akinpelu, O.V., Amusa, Y.B. and Eziyi, A.K. (2009) Epistaxis in Nigerians: A 3-Year Experience. East and Central African Journal of Surgery, 14, 93-98.

[20] Varshney, S. and Saxena, R.K. (2005) Epistaxis: A Retrospective Clinical Study. Indian Journal of Otolaryngology and Head \& Neck Surgery, 57, 125-129.

[21] Ijaduola, G.T.A. and Okeowo, P.A. (1983) Pattern of Epistaxis in the Tropics. The Central African Journal of Medicine, 29, 77-80.

[22] Mgbor, N.C. (2004) Epistaxis in Enugu: A 9-Year Review. Nigerian Journal Otorhinolaryngology, 1, 11-14.

[23] Kaygusuz, I., Karlidag, T., Keles, E., Yalcin, S., Alpay, H.C. and Sakallioglu, O. (2004) Retrospective Analysis of 68 Hospitalized Patients with Epistaxis. Firat Tip Dergisi, 9, 82-85.

[24] Viljoen, J. (2003) Epistaxis in Children: Approach and Management. CME, 21, 664-665.

[25] Elden, L., Reinders, M. and Witmer, C. (2012) Predictors of Bleeding Disorders in Children with Epistaxis: Value of Preoperative Tests and Clinical Screening. International Journal of Pediatric Otorhinolaryngology, 76, 767-771. https://doi.org/10.1016/j.ijporl.2012.02.033

[26] Magy, S., Wahab, A., Fathy, H., Ismaila, R. and Mahmoud, N. (2014) Recurrent Epistaxis in Children: When Should We Suspect Coagulopathy? The Egyptian Journal of Otolaryngology, 30, 106-111. https://doi.org/10.4103/1012-5574.133207

[27] AL-Masum, S.H.I., Arsalan, A.J. and Begum, D. (2015) Epistaxis in Children: Aetiology, Management and Outcome. Bangladesh Journal of Child Health, 39, 73-76. https://doi.org/10.3329/bjch.v39i2.31536 